\title{
INFLUÊNCIA DA VEGETAÇÃO NOS PARÂMETROS MICROMETEOROLÓGICOS DA ÁREA URBANA EM UMA CIDADE DE MÉDIO PORTE DA AMAZÔNIA
}

\author{
Jabert Diniz Júnior ${ }^{1 *}$; Antônio Carlos Lôla da Costa²; Manoel Roberval Pimentel \\ Santos $^{1}$; Luiz Carlos Rabelo Vieira²; Alex Antônio Ribeiro de Oliveira ${ }^{1}$; Leidiane Leão de \\ Oliveira ${ }^{1}$ \\ ${ }^{1}$ Universidade Federal do Oeste do Pará; Santarém-PA, Brasil. \\ ${ }^{2}$ Universidade Federal do Pará; Belém-PA, Brasil \\ *jabert@ufpa.br
}

\begin{abstract}
The study aimed to evaluate the influence of vegetation on the behavior micrometeorological elements in three points with different percentages of vegetation in the city of Santarém-PA. We measured the temperature and relative humidity simultaneously in three squares of the city for five days. The results indicated that, when comparing the squares, the square with the highest percentage of vegetation showed values lower air temperature, while the values of relative humidity were higher in these environments. In comparison within squares, the instruments in the shade of vegetation always recorded the lowest values of average air temperature and the higher the relative humidity. These results indicate an influence of vegetation on the behavior of temperature and relative humidity.
\end{abstract}

\section{RESUMO}

O estudo teve como objetivo avaliar a influência da vegetação no comportamento termohigrométrico em três pontos com diferentes percentuais de vegetação, na cidade de Santarém-PA. Foram medidas a temperatura e a umidade relativa do ar, simultaneamente, em três praças da cidade, durante cinco dias. Os resultados indicaram que, na comparação interpraças, a praça com o maior percentual de vegetação apresentou valores médios de temperatura do ar menores, enquanto que os valores de umidade relativa do ar foram maiores nestes ambientes. Na comparação intrapraças, os instrumentos à sombra da vegetação registraram sempre os menores valores médios da temperatura do ar e os maiores da umidade relativa do ar. Estes resultados indicam que houve influência da vegetação no 
comportamento da temperatura e da umidade relativa do ar.

\section{INTRODUÇÃO}

Dentre os benefícios da vegetação associada ao desenho urbano, Dacanal et al. (2010), em estudo sobre o papel dos fragmentos florestais urbanos no conforto térmico na cidade de Campinas-SP, concluíram que a vegetação densa e estratificada é capaz de atenuar a temperatura do ar, interceptar a radiação solar e manter a velocidade do ar em baixa amplitude, caracterizando ventos leves na Escala Beaufort.

O presente trabalho tem como objetivo avaliar a influência da vegetação no comportamento termohigrométrico em três praças com diferentes configurações morfológicas de SantarémPA.

\section{MATERIAL E MÉTODOS}

O município de Santarém está situado na região norte do país, oeste do estado do Pará, distante cerca de 710 quilômetros da capital Belém, e conta, hoje, com uma população de 294.774 habitantes.

Os instrumentos utilizados nas coletas dos dados meteorológicos foram microloggers, marca HOBO, modelo U10, que foram alojados em abrigos meteorológicos padronizados. Nas três praças, os instrumentos registraram, continuamente, em intervalos horários, a temperatura e a umidade relativa do ar, no período de 11 a 15/04/2011. Para a análise inferencial, verificada a normalidade dos dados através do teste de Shapiro Wilk, foram utilizados o teste $\mathrm{t}$ de Student e o Mann-Whithey - W para a verificação de diferenças entre amostras independentes das variáveis meteorológicas intra e interpraças. Foi adotado $\mathrm{p}<0,05$ para a significância estatística. Para os cálculos, foi utilizado o aplicativo Bioestat ${ }^{\circledR}$ 5.0.

\section{RESULTADOS E DISCUSSÃO}

\section{DIFERENÇAS TERMOHIGROMÉTRICAS INTERPRAÇAS}

A partir da análise estatística, através do teste comparativo de $\mathrm{W}$, pode-se constatar a importância da vegetação. Na Praça do Parque, anexa ao Parque Municipal da Cidade e com o maior percentual de vegetação em seu entorno, as temperaturas médias horárias 
$\left(26,3 \pm 1,6^{\circ} \mathrm{C}\right.$ e $26,7 \pm 2^{\circ} \mathrm{C}$, à sombra e ao sol, respectivamente) foram inferiores às da Praça do Cais de Arrimo, que não possui arborização, com médias horárias iguais a $27,3 \pm 1,4^{\circ} \mathrm{C}$ à sombra e $27,4 \pm 1,5^{\circ} \mathrm{C}$ ao sol, sendo que houve diferença significativa no instrumento à sombra, entre estas duas praças $(p=0,0274)$.

Quanto à umidade relativa, houve diferença significativa entre a Praça Barão de Santarém e a Praça do Cais no instrumento à sombra $(\mathrm{p}=0,0133)$, e entre a Praça do Parque e Praça do Cais, também no instrumento à sombra $(\mathrm{p}=0,0088)$.

\section{DIFERENÇAS TERMOHIGROMÉTRICAS INTRAPRAÇAS}

Na Praça Barão de Santarém, notam-se os menores valores de temperatura no instrumento sob a proteção da radiação solar por vegetação, com valor médio máximo de $28,7^{\circ} \mathrm{C}$. A umidade relativa do ar, por sua vez, no instrumento localizado à sombra, teve os maiores valores.

Na Praça do Parque, com maior percentual de vegetação nas suas proximidades $(32,2 \%)$, notam-se, conforme esperado, os menores valores de temperatura no instrumento à sombra de vegetação, com valor médio máximo de $28,7^{\circ} \mathrm{C}$. A umidade relativa, no instrumento localizado à sombra, apresentou valores ligeiramente menores no instrumento sombreado por árvores.

Na Praça do Cais de Arrimo, com menor índice percentual de vegetação nas suas proximidades $(6,7 \%)$, os menores valores de temperatura foram registrados no instrumento à sombra, porém, apresentou diferenças bem menores entre um instrumento e outro, que nas outras praças. A umidade relativa do ar também apresentou valores ligeiramente menores no instrumento sombreado.

Através do teste $\mathrm{W}$, verificaram-se que, de fato, não houve diferenças significativas entre os valores registrados pelos instrumentos à sombra e ao sol, nem da temperatura $(p=0,7415)$, nem da umidade relativa do ar $(\mathrm{p}=0,1578)$ para os três pontos analisados.

Esses achados estão em consonância com os resultados de outras pesquisas, como dentre os benefícios da vegetação associada ao desenho urbano, Dacanal et al. (2010), em estudo sobre o papel dos fragmentos florestais urbanos no conforto térmico na cidade de Campinas-SP, concluíram que a vegetação densa e estratificada é capaz de atenuar a temperatura do ar, 
interceptar a radiação solar e manter a velocidade do ar em baixa amplitude, caracterizando ventos leves. Barbosa et al. (2003) também constataram, na cidade de Maceió-AL, que a presença de vegetação influenciou nos resultados da pesquisa lá realizada, evidenciando o impacto positivo da vegetação urbana na melhoria das condições microclimáticas, em especial, do rigor térmico, em cidades de clima quente e úmido e de baixa latitude; De Kauffman et al. (2001), em estudo para avaliação de conforto em áreas livres de clima quente úmido, na cidade de Maracaibo, Venezuela, verificaram que a vegetação representa um importante papel na modificação e amenização climática, sobretudo quando se trata de árvores de grande porte.

\section{CONCLUSÃO}

Portanto, que a vegetação influenciou nos dois mecanismos principais para a redução da temperatura do ar: o processo de evapotranspiração, que converte a energia solar em água evaporada ao invés de aumentar a temperatura do ambiente; e o sombreamento, que mantém as superfícies mais frescas, reduzindo a emissão de calor.

Com isso, afirma-se que pesquisas sobre clima urbano são importantes para que se fomentem discussões sobre a qualidade térmica dos espaços livres públicos de cidades da Amazônia brasileira, como Santarém-PA, direcionando a elaboração de projetos arquitetônicos e urbanísticos adequados ao clima da região.

\section{REFERÊNCIAS}

DACANAL, C.; LABAKI, L.C.; SILVA, T. M. L. Vamos passear na floresta! O conforto térmico em fragmentos florestais urbanos. Ambiente Construído, Porto Alegre, v. 10, n. 2, p. 115-132, abr./jun. 2010.

BARBOSA, R. V. R.; BARBIRATO, G. M.; VECCHIA, F. A. S. Vegetação urbana: análise experimental em cidade de clima quente e úmido. In: VII ENCAC e III COTEDI, Anais... Curitiba, 2003.

DE KAUFFMAN et al. Quantifying incidence of the vegetation on the microclimatic Variables in hot-humid climates: "the cují tree". In: 18th international conference on passive and low energy architecture - plea, Anais... Brasil, 2001. p.577-582. 